\title{
Twin-Twin Transfusion Syndrome
}

National Cancer Institute

\section{Source}

National Cancer Institute. Twin-Twin Transfusion Syndrome. NCI Thesaurus. Code C113824.

A condition which occurs in monozygotic twins in which one of the fetuses supplies the majority of the cardiac output to its co-twin through its umbilical artery. The recipient twin has only rudimentary organs and structure and is not viable. 